ESTRATÉGIA 


\title{
MODELO DECISÓRIO DE UMA MULTINACIONAL BASEADO EM SISTEMAS E FLUXOS INFORMACIONAIS
}

\author{
DECISION-MAKING MODEL OF A MULTINATIONAL COMPANY BASED \\ ON INFORMATION SYSTEMS AND FLOWS
}

Frederico Cesar Mafra Pereira

Fundação Pedro Leopoldo

Wesley Pedro Sobrinho

Faculdade Pitágoras

Ricardo César Alves

Pontifícia Universidade Católica de Minas Gerais
Data de submissão: 25 abr. 20|7. Data de aprovação:

20 nov. 2017. Sistema de avaliação: Double blind review.

Universidade FUMEC / FACE. Prof. Dr. Henrique Cordeiro

Martins. Prof. Dr. Cid Gonçalves Filho.

\section{RESUMO}

Este trabalho apresenta uma análise de como os sistemas de informação (SI) são utilizados nos processos decisórios de uma empresa multinacional, com fins à produção de louças sanitárias. Foi realizado um estudo de caso de natureza descritiva qualitativa, via métodos de coleta a partir de entrevistas semiestruturadas, realizadas junto ao corpo diretivo e gerencial da organização, pesquisa documental e observação participante. A partir do 'Modelo para Tomada de Decisões Estratégicas Baseado em Sistemas e Fluxos Informacionais', proposto no trabalho, com base no modelo original de Mafra Pereira (20II), foi possível identificar e perceber o uso consistente dos SI nas decisões mencionadas pelos gestores, com destaque para sua utilização nas ações de identificação, obtenção, avaliação e registro das informações. Os resultados indicaram também a capacidade interativa e de complementaridade dos SI utilizados, tornando a informação mais completa e permitindo a assertividade no momento da tomada de decisão.

PALAVRAS-CHAVE

Processo Decisório. Sistemas de Informação. Fluxos Informacionais. Modelos para Tomada de Decisão. 


\section{ABSTRACT}

This work presents an analysis of how information systems (IS) are used in the decision-making processes of a multinational company ends the production of sanitary wares. A case study of a qualitative descriptive nature was carried out, through collection methods from semi-structured interviews, carried out with the strategic board and organization's managers, documentary research and participant observation. Based on the original model of Mafra Pereira (20I I), it was possible to identify and perceive the consistent use of IS in the decisions mentioned by the managers, based on the model for strategic making decisions based on information systems and flows, with emphasis on its use in identifying, obtaining, evaluating and recording information. The results also indicated the interactive and complementary capacity of the IS used, making the information more complete and allowing assertiveness at the time of decision making.

\section{KEYWORDS}

Decision Making. Information Systems. Information Flows. Decision-Making Models.

\section{INTRODUÇÃO}

As últimas décadas do século $\mathrm{XX}$ deram início à 'Era da Informação e do Conhecimento', em que a possibilidade de aumento da capacidade analítica evoluiu com o avanço tecnológico, e sua participação e influência no processo de tomada de decisão ganhou, definitivamente, espaço relevante nas questões que envolvem a gestão das organizações. Ao se defrontarem com novos desafios, as organizações e pessoas precisam estar preparadas e atualizadas para a possibilidade de mudanças constantes, com novas formas de fazer, de interagir com mercados, clientes, tendências tecnológicas e econômicas, sociais e culturais, e sempre com foco e objetivo em melhorar a eficácia e eficiência dos produtos, processos ou serviços. A capacidade de tomada de decisão baseada na informação é a cha- ve para o sucesso das pessoas e do mundo organizacional, sendo este pautado no sucesso individual dos gestores enquanto tomadores de decisão, na capacidade de cada um em alinhar as percepções, experiências e ações no sentido de buscar as melhores opções e estratégias.

Alvarenga Neto (2008) afirma que a tomada de qualquer decisão só se confirma se dispuser das informações necessárias, existindo, neste sentido, a busca pelo entendimento dos aspectos que envolvem a tomada de decisão. Oliveira (2014) considera que a tomada de decisão se caracteriza pela conversão das informações analisadas em ação efetiva, sendo, geralmente fomentada por situações problemáticas, oriundas das atividades complexas do ambiente organizacional, do não cumprimento das metas estipuladas e das condições adversas no cumprimento das 
normas e regras gerais das organizações. Assim, torna-se oportuno entender o processo de tomada de decisão nas organizações como um fluxo informacional e seu impacto para que os decisores possam fazer uso da quantidade, qualidade e momentos corretos da informação.

A pesquisa aqui relatada foi realizada em uma indústria, denominada neste trabalho como "Organização Alfa" - empresa de grande porte localizada em Santa Luzia -MG, atuante no mercado da construção civil há mais de 85 anos, com larga experiência nos processos de fabricação de louças sanitárias e artigos similares, constituinte de um grande conglomerado mundial no segmento - tendo como objeto de estudo o uso dos sistemas de informação (SI) como suporte às decisões estratégicas tomadas por seus gestores.A partir do 'Modelo para Tomada de Decisões Estratégicas Baseado em Sistemas e Fluxos Informacionais', proposto neste trabalho, e configurado com base no modelo original de Mafra Pereira (20II), buscou-se responder a seguinte questão: como os sistemas de informação (SI) são usados nos processos de tomada de decisão em uma grande empresa multinacional? Dessa forma, o objetivo geral foi analisar como os SI são usados nos processos de tomada de decisão organizacional nesta grande empresa, com base no modelo proposto. Para tanto, alguns objetivos específicos foram também definidos: (i) descrever as funcionalidades dos SI da organização alvo do estudo; ii) identificar quais fatores e sistemas são utilizados pelos gestores nos processos de decisão, e; iii) identificar como os SI suportam as decisões.

Este trabalho foi desenvolvido a partir de uma abordagem metodológica de na- tureza descritiva qualitativa, via estudo de caso, no qual a unidade de análise compreendeu os SI da Organização Alfa, e as unidades de observação os seus gestores, responsáveis pelas tomadas de decisões estratégicas em vários níveis, com atuações distintas nas áreas e setores da organização. Junto a estes gestores foram realizadas entrevistas individuais via aplicação de um roteiro semiestruturado referente ao processo decisório avaliado.

Além desta introdução, o artigo se compõe de mais quatro capítulos. $O$ capítulo dois apresenta o referencial teórico e as contribuições teóricas e metodológicas utilizadas para a proposição do 'Modelo para Tomada de Decisões Estratégicas baseado em Sistemas e Fluxos Informacionais' utilizado como direcionador da pesquisa aplicada e a análise dos dados. No capítulo três são explicitados os procedimentos metodológicos, com a apresentação da empresa participante, as características da unidade de análise (SI) e das unidades de observação (gestores). No capítulo quatro são apresentados os resultados obtidos através das entrevistas semiestruturadas realizadas com os gestores para teste e validação do modelo proposto. No capítulo cinco são apresentadas as conclusões e considerações finais do trabalho, além das recomendações de novos estudos.

\section{REFERENCIALTEÓRICO}

$O$ contexto informacional nas organizações

Tarapanoff (2006, p.23-24) considera ser fundamental que as informações sejam processadas e gerenciadas de acordo com os princípios, procedimentos e orientações estabelecidos pelo modelo de gestão da organização. Alvarenga Neto (2008) ressalta a importância da cultura organiza- 
cional e seu sistema de valores, conciliando -os com as estratégias adotadas, e aponta que a Gestão de Recursos Informacionais (GRI) deve apoiar e fortalecer os objetivos corporativos, apresentando respostas aos problemas que as organizações enfrentam. Barbosa (2008) aponta outros fatores críticos, como a organização e o tratamento da informação, e define que para melhor gerenciar o volume de informações produzidas, torna-se necessário a adoção de um sistema capaz de processar o conteúdo informacional dos documentos, possibilitando sua futura recuperação.

Segundo Audy et al. (20ll), a importância dos aspectos estratégicos da informação no contexto organizacional apresenta-se já consolidada. A questão a ser discutida nos dias atuais é quando e como as tecnologias da informação ( $\mathrm{TI})$ afetarão as organizações. Ao discutirem o papel estratégico da informação e dos sistemas da empresa, Rezende \& Abreu (2003) afirmam que quanto maior o valor e a qualidade da informação, maior a probabilidade de acerto na tomada de decisão. Todavia, Siqueira (2005) explica que as organizações se distinguem pelo que elas sabem e pela forma como conseguem utilizar suas informações e tomar as decisões. Para tanto, as organizações necessitam desenvolver habilidades em transformar a imensa massa de dados que circulam periodicamente, em informações consistentes, que possam agregar valor ao negócio. No trato da informação, agregar valor ao negócio significa suportar da melhor forma possível - com o mínimo de impacto nas atividades organizacionais - o processo de tomada de decisão com informações de qualidade.

Para Choo (2006), o processamento da informação deve ocorrer de maneira inte- rativa; as informações devem ser utilizadas de acordo com a experiência, vivência e educação de cada indivíduo, possibilitando a atuação e a tomada de decisão. Assim, a aquisição da informação deve atender a duas demandas principais: amplitude adequada para atender às necessidades, e uso de uma seleção que seja capaz de atender às limitações humanas, sejam pela capacidade de atenção ou pelos aspectos cognitivos. Sob esta ótica, Bio (1996) considera a informação como de dois tipos: operacional, que é aquela destinada à operacionalização de um processo ou de um trabalho; e gerencial, sendo destinada a um processo de análise e tomada de decisão.

A informação também pode ser considerada como a memória da organização. Neste sentido, o processo de organização e armazenamento da informação tem relevância, pois contribui para entender os processos, o passado, a evolução e o futuro de uma organização. Choo (2006) explica que a forma como a informação é armazenada influencia na maneira como a organização percebe o seu ambiente, permitindo ser acessada com facilidade e resgatada sempre que houver necessidade.

$\mathrm{Na}$ perspectiva de Davenport (1999), quando se entende a administração informacional como um processo, surge a gestão da informação (GI). Neste sentido o autor conceitua a GI como um conjunto estruturado de atividades que consideram o modo como as organizações obtêm, distribuem e usam a informação e o conhecimento. Moraes \& Escrivão Filho (2006) comentam que o processo de $\mathrm{Gl}$, para ser estratégico, deve ser contínuo, destacando que a informação compreende todo o dado trabalhado, tratado, com valor significativo atribuído ou agregado, com um sentido ló- 
gico para quem utiliza a informação. Choo (2006) afirma que a eficácia deste processo é maior quando as informações necessárias alcançam aqueles que dela farão o melhor uso. Quando as informações estão identificadas e definidas, as decisões dos atores participantes torna-se mais segura.

Estender at al. (2016) compreendem a Gl como um conjunto de estratégias que apontam as necessidades formais e informais das organizações, apoiando o desenvolvimento das atividades cotidianas e a tomada de decisão no ambiente corporativo, visando a melhoria continua dos processos e o entendimento dos objetivos organizacionais. E Cunha, Mafra Pereira \& Neves (2015) destacam que a relação entre dados, informação e conhecimento nas organizações culminam em fluxos informacionais, que, por consequência, apoiam a tomada de decisão.

Sistemas de Informação: tipologias voltadas à tomada de decisão empresarial

Os Sistemas de Informação (SI) são definidos por Schwartz (1970) como um sistema de pessoas, procedimentos, documentos, equipamentos e comunicações que valida, transforma, armazena, recupera e apresenta dados para uso em processos gerenciais com vários objetivos organizacionais. Ein-Dor \& Segev (1983) apontam que os $\mathrm{SI}$ estão voltados para a coleta, armazenagem, recuperação e processamento de informações úteis aos executivos, e que podem ser utilizados no desempenho de suas atividades gerenciais. Para Nash \& Roberts (1984), SI são uma combinação de pessoas, facilidades, ambientes, tecnologias, procedimentos e controles que tem por finalidade manter os canais de comunicação essenciais às rotinas típicas, além de servirem de alertas de eventos internos e externos e proporcionam aos executivos base para tomada de decisão inteligente. Gordon \& Gordon (2006) apresentam uma definição de $\mathrm{SI}$ que combina $\mathrm{TI}$ com dados, procedimentos para processar dados e pessoas que os coletam e fazem uso deles. Para os autores, é fundamental que as organizações utilizem uma variedade de sistemas para auxiliar na GI, sendo variadas as suas aplicações, desde o desempenho de empregados, preferencias de clientes, evolução de produtos e processos, bem como em tomar decisões em negociar e gerir recursos. E Laudon \& Laudon (20I I) classificam os $\mathrm{SI}$ conforme a finalidade a que se destinam: i) de nível operacional: monitoram as tarefas, atividades e transações elementares da organização; ii) de nível de conhecimento: auxiliam na integração de novos conhecimentos e no controle de fluxo de papéis; iii) de nível gerencial: monitoramento, controle e tomada de decisão em atividades administrativas dos gestores; iv) de nível estratégico: auxiliam os gestores no planejamento de suas atividades, e aplicam-se, sobretudo, no planejamento de longo prazo.

Em especial, os Sistemas de Informação Gerenciais (SIG) são considerados por Bio (1996) como aqueles que podem responder a uma gama de necessidades de informação para a tomada de decisão. Guimarães (2000) defende que as fontes de informações utilizadas nos SIG podem ser internas ou externas à organização, e que esses devem subsidiar 3 funções básicas na organização: i) resolução de problemas; ii) produção do conhecimento; iii) tomada de consciência com relação aos problemas. Para Oliveira (20I4) os SIG podem ser entendidos como um processo de 
transformação de dados em informações, sendo utilizados na estrutura decisória da organização, tendo como objetivos coletar, validar, executar operações, transformar, armazenar e apresentar informações para o uso do planejamento organizacional e gerencial, além de extraírem informações de base de dados e de processos, a fim de prover os decisores com informações do passado e do presente, sobre as operações internas e do ambiente organizacional. A tomada de decisão passa a ser pautada na análise dos dados, fazendo com que os objetivos traçados sejam obtidos de modo satisfatório. Assim, os SIG influenciam as várias áreas funcionais da organização no nível tático, promovendo um nível adequado de interação e necessidade de ações. Oliveira (2014) ainda argumenta que os SIG são responsáveis por fornecer conceitos, métodos, técnicas e ferramentas para que os gestores tomem decisões apoiados em informações estratégicas, precisas e atualizadas. $O$ autor considera que estes sistemas são fontes de apoio à tomada de decisão, que levam em conta requisitos quanto aos transmissores e receptores de informações, canais de transmissão, bem como processos de tomada de decisão junto aos centros de responsabilidades das organizações.

Os Sistemas de Suporte à Decisão (SAD) também possuem como fundamento o apoio à tomada de decisões empresariais. Para Sprague \& Watson (199I), apresentam como características principais o uso de modelos e de dados de fontes distintas, a preocupação com o estilo de gestão do decisor e a possibilidade de simulação. Stair (1998) conceitua-o como um sistema de interface simples e processamento complexo, capaz de obter informações a partir de inú- meras fontes, internas ou externas à organização. Para Laudon \& Laudon (20I I), o SAD considera a forma analítica dos decisores em relação aos dados, isto é, a quantidade de informações quantitativas e qualitativas, o uso de tabelas e gráficos disponíveis para a leitura correta do contexto. E Oliveira (20I4) afirma que o SAD, comparado com o SIG, tem uma abordagem mais flexível e ágil, apoiado por estilos pessoais de decisão, com uma abordagem específica das necessidades dos usuários do sistema.

Os Sistemas de Informações para Executivos ou Enterprise Information System (EIS) têm como público alvo gestores de nível estratégico das organizações. Furlan et al. (1994) apresentam como características deste tipo de sistema: i) elimina o intermediário entre o executivo e o computador; ii) adapta-se ao estilo de decisão do executivo; iii) é de fácil acesso e utilização; iv) fornece uma visão global e precisa da organização; v) possui recursos gráficos, de alta qualidade e capacidade de drill down (visualização das informações em vários níveis de detalhes); vi) gera relatórios com diversificados tipos; vii) mantém o enfoque para identificação de necessidade de informações que apresentem fatores críticos de sucesso. Para Gordon \& Gordon (2006) os EIS apresentam similaridades com os SAD; entretanto, os EIS satisfazem às exigências mais amplas dos gestores, reconhecendo tendências e determinando causas encobertas ou com difícil visibilidade entre as informações disponibilizadas por outros SI. Laudon \& Laudon (20II) reforçam esta visão considerando que o principal objetivo dos EIS é a filtragem dos dados mais relevantes para que os gestores tomadores de decisão, obtendo informações com redução de tempo. 
Processos decisórios: conceitos e modelos

Para Angeloni (2003), a decisão é considerada como um sistema ou um processo linguístico e coletivo, caracterizada pela interferência das diferenças individuais na coleta e interpretação da informação. A autora reforça que uma decisão tomada é afetada pela informação disponível e processada pelos indivíduos. A maneira e os meios com os quais a informação é analisada e, posteriormente avaliada, transformam-se em valor que pode influenciar todos os processos e métodos da organização. Já Mintzberg (2004) considera que uma decisão organizacional é um comprometimento específico para a ação, usualmente de recursos e, que o processo decisório é um conjunto de ações e fatores que se inicia na identificação de estímulos para a ação e termina com o comprometimento para ela. Para ele, a decisão é estratégica quando considerada relevante para os gestores da alta administração em relação às ações a serem tomadas, dos recursos comprometidos ou dos precedentes estabelecidos, envolve posicionamento estratégico e apresenta altos riscos.

Segundo Pereira \& Fonseca (2009), na vida organizacional pode-se observar dois tipos de decisões: aquelas que os gerentes tomam em sua rotina de trabalho, que se configuram como programáveis e previsíveis, e aquelas que the são solicitadas eventualmente, de forma imprevisível e sem uma programação.As decisões são do tipo 'estratégicas' quando estão relacionadas a grandes mudanças no ambiente organizacional, que impactam no futuro e promovem transformações profundas, seja na cultura organizacional, nas tecnologias utilizadas ou nos comportamentos dos indivíduos.

Para Oliveira (2014) quando ocorre o aumento da complexidade interna nas organizações e no ambiente em que atuam, o processo decisório tende a tornarse também mais complexo. Para atender a essa demanda de maneira adequada, os executivos necessitam de $\mathrm{SI}$ eficientes e eficazes, que consigam processar grande volume de dados gerados, produzindo informações válidas.

Para Choo (2006), o processo decisório consiste em esforços direcionados na busca de alternativas que sejam boas 0 suficiente, em detrimento da melhor alternativa existente, e propõe um esquema de tomada de decisões que está baseado na criação de significado a partir das informações e da construção do conhecimento. $\mathrm{O}$ autor condensa a existência de quatro principais modelos de tomada de decisão utilizados nas organizações, sob a ótica da informação (fluxo e comportamento informacional): o "modelo racional" (MARCH; SIMON, 1975; MARCH, 1994), o "modelo processual" (MINTZBERG; RAISINGHANI; THÉORÊT, 1976), o "modelo político" (ALLISON, I97I; PFEFFER; SALANCIK, 1974; MELTSNER, 1976) e o "modelo anárquico" (COHEN; MARCH; OLSEN, 1972).

Mafra Pereira (20II) desenvolveu O 'Modelo Geral para Tomada de Decisão Estratégica em Empresas de Pequeno Porte', baseado nos argumentos de Choo (2006), e que é formado por três momentos principais: a pré-decisão, a decisão em si e a pós-decisão. A pré-decisão é marcada por quatro passos distintos. $O 1^{\circ}$ passo busca identificar os reais motivos que levaram à necessidade de tomada de decisão, considerados pelo tipo de informação que influenciou ou disparou tal processo. Neste passo também é objetivo buscar a identificação de quem foi o responsável pelo 
levantamento da necessidade de informação e de decisão, podendo ser ou não o decisor final. $O 2^{\circ}$ passo tem a intenção de levantar as informações necessárias para a tomada de decisão, e que muitas vezes não estão disponíveis ou acessíveis ao decisor. No $3^{\circ}$ passo, Mafra Pereira (20I I) aponta para a importância de se identificar onde o usuário obteve as informações necessárias, e são consideradas as fontes de informação utilizadas, bem como as razões para tal escolha, os meios de comunicação e o formato das fontes. $O 4^{\circ}$ e último passo é o momento da discussão do conteúdo informacional obtido pelo processo anterior, ou seja, o resultado final do processo de busca informacional.

O segundo momento presente no modelo proposto por Mafra Pereira (20II) refere-se à decisão em si ( $5^{\circ}$ passo); nele tem-se o objetivo de identificar, dentre as fontes e informações obtidas, aquelas que mais influenciaram na tomada de decisão. Neste momento, o autor argumenta a importância de também se identificar outros fatores que possam ter influenciado na tomada de decisão, como o tempo disponível para decidir, a experiência do decisor, a intuição, dentre outros.

O terceiro momento do modelo, de pósdecisão, tem o objetivo de levantar informações sobre a implementação da decisão escolhida ( $6^{\circ}$ passo); seguido da avaliação dos resultados obtidos ( $7^{\circ}$ passo) e o registro da decisão na forma de documentos, procedimentos ou princípios a serem adotados em futuras decisões similares ( $8^{\circ}$ passo).

\section{Marco Teórico: contribuições}

do referencial teórico

Fundamentado no modelo proposto por Mafra Pereira (20II), este trabalho adotou algumas adaptações ao modelo referenciado, considerando a presença dos SI no auxílio aos decisores durante o processo de decisão, considerando as visões complementares de Lima (20I5), de que existem três papéis fundamentais que um SI pode exercer nas organizações: i) no suporte a seus processos e operações de negócios; ii) na tomada de decisão pelos seus empregados e gerentes e; iii) no suporte às suas estratégias para obtenção de vantagem competitiva e de Silva, Rodrigues \& Silva (20I5), que afirmam que os $\mathrm{Sl}$ surgem com a necessidade de proporcionar agilidade, praticidade e o auxílio no planejamento para toda e qualquer decisão que acarrete um grande impacto em uma organização.

A pesquisa desenvolvida neste trabalho manteve o foco nos SI como suporte à tomada de decisão estratégica em organizações. Considerando este ponto de vista, foi proposto o 'Modelo para Tomada de Decisões Estratégicas baseado em Sistemas e Fluxos Informacionais', apresentado na figura I. Além dos passos já considerados no modelo de Mafra Pereira (20 I I), foram agregadas em vários passos questões que norteiam a decisão a partir da utilização dos Sl, além de um nono passo, referente à divulgação da decisão.

Considerando os SI como um constructo da tomada de decisão utilizado no modelo proposto, passar-se-á a considerar sua análise e aplicação nos seguintes passos:

I. Passo I (pré-decisão): propõe-se o uso dos SI no processo de identificação dos motivos que despertaram a necessidade de se tomar a decisão, carregando a informação que disparou a necessidade;

II. Passo 3 (pré-decisão): propõe-se o uso de SI como fontes que sustentam 


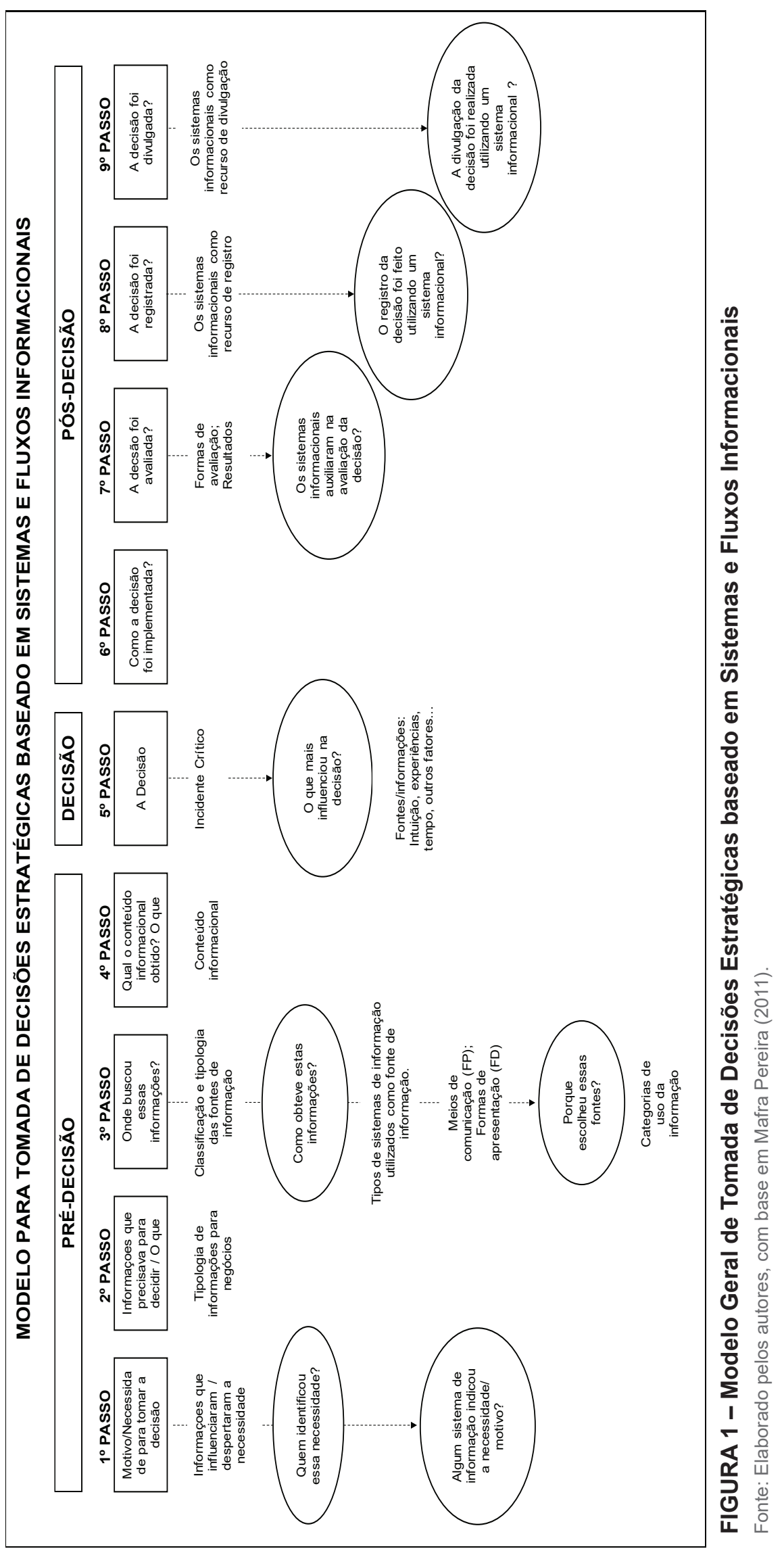


a informação primordial no momento da decisão, além da reflexão sobre a importância dos SI como fontes documentais, seus tipos e aspectos que envolvem a confiabilidade, a relevância e a qualidade dos mesmos no processo decisório;

III. Passo 7 (pós-decisão): o modelo procura identificar a participação dos SI não só na avaliação da decisão, como na sustentação dos resultados obtidos;

IV. Passo 8 (pós-decisão): o modelo procura evidenciar a existência dos SI como recurso para o registro da decisão, as possibilidades deste registro, sua importância como meio formal de manutenção da decisão;

V. Passo 9 (pós-decisão): neste último passo busca-se identificar se a decisão tomada foi divulgada na organização. Este novo passo proposto pretende identificar se os decisores reconhecem a divulgação da decisão tomada como parte do processo utilizado. Ressalta-se a reflexão sobre as possibilidades que a divulgação das decisões possa proporcionar à organização, no sentido de levar ao conhecimento dos outros gestores a definição final das ações tomadas, fomentando a troca de informações sobre situações críticas, reduzindo o tempo para se tomar a decisão, evitando desperdícios e aumentando a eficácia dos processos.

\section{PROCEDIMENTOS METODOLÓGICOS}

Este estudo classifica-se, quanto aos fins, como do tipo descritivo (MALHOTRA, 200 I; GIL, 2002; COLLIS; HUSSEY, 2005; VERGARA, 2007), propondo-se a descrever a realidade com o objetivo de apre- sentar aspectos que favoreçam o fluxo de informação no processo de decisão, utilizando para tanto o Modelo para Tomada de Decisões Estratégicas baseado em Sistemas e Fluxos Informacionais proposto. Quanto aos meios, trata-se de um estudo qualitativo (GIL, 2002), sendo utilizado o método de estudo de caso (BRUYNE, I991; YIN, 2005; COOPER; SCHINDLER, 20 I I).

A organização considerada para a pesquisa, denominada "Organização Alfa" (nome fictício), prestou-se a toda fundamentação experimental desenvolvida neste trabalho, havendo o consentimento da organização aos fins do estudo. A Organização Alfa faz parte de uma holding que iniciou suas atividades na década de 1930 na cidade de Barcelona, Espanha, produzindo radiadores de ferro fundido para uso doméstico no aquecimento das residências. Neste período, este grupo começou a produzir utensílios para banheiros à base de metais, como banheiras e torneiras. $\mathrm{Na}$ década de 1990, o grupo incorporou várias fábricas no Brasil, mantendo presença fabril também em Portugal, Rússia,Argentina, China, Índia. Atualmente a organização estende sua rede comercial para 135 países, abastecidos por 76 fábricas, alcançando liderança mundial desde o ano de 2006. A Organização Alfa, uma das quatro unidades fabris do Brasil, conta com 1040 funcionários diretos, 25 gestores (supervisores e coordenadores) e 3 gerentes (I gerente industrial e 2 gerentes de produção), e produz 350.000 peças mensalmente, sendo a maior fábrica de louças no mundo.

Mazzotti \& Gewandsznajder (1999) definem a unidade de análise como a forma que os dados são organizados para efeito da análise em uma pesquisa qualitativa, eYin (2005) argumenta que a unidade de análise 
corresponde aos aspectos que definem e limitam o "caso". Para o presente estudo, foi considerado como unidade de análise o constructo "sistemas de informação", dada a sua relação com os temas que referentes às decisões empresariais e ao modelo proposto, o qual carrega a sustentação da relação entre tomada de decisão e sistemas de informação. Os gestores da Organização Alfa caracterizam as unidades de observação da pesquisa. Gil (2002) argumenta que uma unidade de observação deve ser constituída por um indivíduo a ser observado em um tempo definido. A definição das unidades de observação foi baseada na amostragem do tipo não probabilística por julgamento (ou intencional) (MATTAR, 1996; MAFRA PEREIRA, 2000), sendo considerados todos os gestores residentes, isto é, que estão alocados e atuam integralmente na Organização Alfa. Reverenciando aspectos da representatividade e da credibilidade da pesquisa, definiu-se, como critério de inclusão/exclusão, que as unidades de observação contemplariam gestores com no mínimo dois anos de experiência na gestão da organização pesquisada. Este ponto de corte foi decidido considerando-se a complexidade dos processos desenvolvidos na Organização Alfa, sendo este um tempo mínimo para que os gestores com menor experiência pudessem já ter presenciado alguns ciclos de processos decisórios, suas limitações e oportunidades, e desenvolverem-se com maturidade e criticidade adequadas dentro da organização.

A coleta de dados foi caracterizada pela triangulação de fontes de coleta de dados qualitativos, oriundas das entrevistas em profundidade com os gestores, da observação participante e da pesquisa documental. Assim, a estruturação metodológica bus- cou, a partir destes procedimentos, aumentar a generalização do estudo e minimizar os vieses pessoais que poderiam existir (VERGARA, 2007).

Com relação às entrevistas em profundidade, estas foram realizadas através da aplicação de um roteiro semiestruturado (TRIVIÑOS, 1987) junto aos gestores da Organização Alfa. O momento central da entrevista caracterizou-se pela escolha de um momento crítico de tomada de decisão, utilizando-se da técnica do Incidente Crítico (FLANAGAN, 1954). Para Carrol et al. (1993) a técnica do Incidente Crítico foca em um incidente considerado importante, usada em estudos de necessidades como na definição de requisitos de sistemas, nos estudos de comportamento de busca de informação bem como na aplicação em estudos de usos e necessidades de informação.

Com relação à observação participante, Sanday (1984) afirma que o observador participante deve aprender a usar sua própria pessoa como o principal e mais confiável instrumento de observação, seleção, coordenação e interpretação, e interagindo com os sujeitos da pesquisa, se tornando parte da situação observada. Segundo Oliveira (2010), em pesquisa qualitativa o pesquisador faz parte da pesquisa, sendo ele o primeiro instrumento da pesquisa, pois traz consigo a bagagem intelectual e experiência de vida, traduzindo a pesquisa através das características culturais, políticas e religiosas, étnicas, até da idade que carrega. Considerando a Organização Alfa, um dos autores deste trabalho também faz parte do corpo gestor, e atuou como observador participante.

A técnica de pesquisa documental (GIL, 2002; FIGUEIREDO, 2007) foi utilizada como meio de explorar e caracterizar os SI utilizados na organização, dado que os SI 
se constituem os meios pelos quais documentos podem ser acessados, consultados e analisados em toda a extensão que se apresentem, podendo ser melhorados ao longo do tempo, seja por questões que privilegiam a análise, seja por necessidade de tomada de decisão daqueles que deles fazem uso.

Com relação à análise dos dados qualitativos, foi utilizada a análise de conteúdo, a qual, segundo Bardin (2002), constitui-se de técnicas em que se busca descrever o con- teúdo emitido no processo de comunicação, seja ele verbal ou por meio de textos.

\section{APRESENTAÇÃO E ANÁLISE DOS RESULTADOS}

Pesquisa documental: Sistemas de

Informação da Organização Alfa

Vários SI foram identificados e descritos como sendo utilizados pelos gestores da Organização Alfa, na tomada de decisão estratégica empresarial, conforme Quadro I:

QUADRO 1 - Sistemas de Informação da Organização Alfa

\begin{tabular}{|c|c|}
\hline SI da Organização Alfa & Características \\
\hline PMI - Plan Management I & $\begin{array}{l}\text { Sistema integrado desenvolvido pela organização, utilizado para coletar e preservar os } \\
\text { dados dos setores de fabricação de massa, fabricação de esmalte, fundição cerâmica, fun- } \\
\text { dição de moldes e esmaltação cerâmica. Funciona na captação e preservação do banco } \\
\text { de dados, sendo utilizado como fonte de informação para outros SI, como o SEP (Sistema } \\
\text { Estatístico de Produção) e SAP (do alemão: Systeme, Anwendungen und Produkte) ou } \\
\text { Sistemas e Aplicativos e Produtos para Processamento de dados. }\end{array}$ \\
\hline PMII - Plan Management II & $\begin{array}{l}\text { Sistema integrado desenvolvido pela organização, utilizado similarmente ao PMI. Atua na } \\
\text { coleta e preservação dos dados de produção compreendendo os setores de tratamento } \\
\text { térmico (fornos), controle de qualidade final e requeima. Analogamente ao PMI, este siste- } \\
\text { ma é utilizado também como fonte de informação para o SEP e SAP. }\end{array}$ \\
\hline $\begin{array}{l}\text { SEP - Sistema Estatístico } \\
\text { de Produção }\end{array}$ & $\begin{array}{l}\text { Sistema informatizado desenvolvido pela organização, utilizado para registro e consulta da } \\
\text { produção, mantendo a informação de todas as fases do processo. Utilizado desde } 2013 \text {, } \\
\text { possibilita aos usuários consultas mensais, diárias ou anuais, por setores e por fases, por } \\
\text { máquinas ou equipamentos, seja para análise de um único produto ou mesmo de um grupo } \\
\text { deles. Permite a inserção de valores de limites de processo, para acompanhamento de } \\
\text { metas, tanto para os dados produtivos, quanto para as anomalias. Possibilita, ainda, a aná- } \\
\text { lise gráfica das variáveis, gerando possibilidades de cruzamento de dados, e dando aos } \\
\text { decisores possibilidades diversas de análise. Durante a pesquisa este sistema mostrou-se } \\
\text { amplamente utilizado pelos gestores da Organização Alfa. }\end{array}$ \\
\hline $\begin{array}{l}\text { SAP - (do alemão: Systeme, Anwen- } \\
\text { dungen und Produkte) ou Sistemas e } \\
\text { Aplicativos e Produtos para Proces- } \\
\text { samento de dados }\end{array}$ & $\begin{array}{l}\text { Oferece um conjunto de módulos integrados, com diversas aplicações de negócio, e con- } \\
\text { tém a maior parte das funcionalidades necessárias às grandes corporações, incluindo ma- } \\
\text { nufatura, finanças, vendas e distribuição e recursos humanos. Oferece o processamento } \\
\text { de informações em tempo real ao longo da empresa onde estiver implementado. }\end{array}$ \\
\hline $\begin{array}{l}\text { Análitico (Informativo de qualidade } \\
\text { diário) }\end{array}$ & $\begin{array}{l}\text { Sistema integrado desenvolvido pela organização, que utiliza os recursos do sistema Offi- } \\
\text { ce } 2010 \text { (Microsoft Corporation), para coleta dos dados do SEP. Apesar de trabalhar com } \\
\text { os mesmos dados do SEP, possibilita análises por tabelas e gráficos que podem ser elabo- } \\
\text { radas e manipuladas pelo usuário. A criação deste SI teve como objetivo inicial melhorar a } \\
\text { interface com o usuário, facilitando a manipulação dos dados. Posteriormente observou-se } \\
\text { que este SI proporcionava maior comodidade na obtenção dos dados, por apresentar me- } \\
\text { Ihor interface de navegação, possibilidades de estratificações dos dados, com a utilização } \\
\text { de tempo reduzido, se comparado com o SEP. }\end{array}$ \\
\hline ApData GA - Global Antares & $\begin{array}{l}\text { Sistema integrado e automatizado utilizado na gestão de recursos humanos, adquirido } \\
\text { pela organização, com fins à administração de pessoal, no controle de ponto de acesso, } \\
\text { na gestão complementar (processos judiciais, pesquisas e gestão de contratos), e na me- } \\
\text { dicina e segurança. Existe acesso regulado para informações de cada gestor, dependendo } \\
\text { do seu cargo e finalidades. Foi também amplamente citado pelos gestores entrevistados, } \\
\text { como um sistema secundário de apoio à decisão empresarial. }\end{array}$ \\
\hline $\begin{array}{l}\text { Planilhas eletrônicas de } \\
\text { uso individual }\end{array}$ & $\begin{array}{l}\text { Sistemas de controle dos processos setoriais confeccionadas pelos próprios gestores, de- } \\
\text { senvolvida nos sistemas Office } 2010 \text {. Citadas eventualmente pelos gestores durante as } \\
\text { entrevistas como um recurso adicional aos sistemas de informação corporativos, supor- } \\
\text { tando e apoiando no registro de dados e informações dos processos produtivos. Tratam-se } \\
\text { de planilhas simples, mas que carregam valor agregado pelas possibilidades de tomada de } \\
\text { decisão estratégica, ora setoriais, ora gerenciais, dependendo do tipo de usuário. }\end{array}$ \\
\hline
\end{tabular}




\begin{tabular}{|l|l|}
\hline Krontime & $\begin{array}{l}\text { Plataforma de utilização no setor de Métodos e Processos, adquirida pela organização, e } \\
\text { desenvolvida pela empresa Krontime, que possibilita a coleta de dados com fins a controlar } \\
\text { a produtividade e eficiência dos processos. Apresenta recursos para controle e análise de } \\
\text { padronizações entre unidade de produção, registro de métodos de trabalho, acompanha- } \\
\text { mento do processo de produção e desempenho nos postos de trabalho, além de facilitar o } \\
\text { planejamento e gestão de projetos de melhoria a partir de uma abordagem estruturada. Na } \\
\text { Organização Alfa, sua utilização destina-se ao registro das medições de tempos de tarefas } \\
\text { e atividades operacionais. Apresenta ao gestor do setor de Métodos e Processos várias } \\
\text { possibilidades de análise de desempenho da mão de obra, dos processos e caminhos } \\
\text { críticos, análise de filas de produção, bem como na tomada de decisão estratégica, seja } \\
\text { setorial, quando se trata de ações localizadas, ou quando há situações em que eviden- } \\
\text { ciam-se oportunidades empresariais. }\end{array}$ \\
\hline GP - Gestão da Produção & $\begin{array}{l}\text { Sistema integrado que possibilita a captação, registro e análise das informações relaciona- } \\
\text { das ao desempenho da mão de obra. Sistema corporativo desenvolvido pela organização, } \\
\text { que apresenta a possibilidade de análises gráficas comparativas, seja entre operações } \\
\text { setoriais, seja na avaliação do desempenho da organização, ou mesmo nas avaliações } \\
\text { entre as unidades produtivas da holding. É utilizado por todos os gestores como meio de } \\
\text { registro das atividades realizadas no setor, e como fonte de informação no momento de } \\
\text { análise das oportunidades relacionadas à gestão da mão de obra, bem como na tomada } \\
\text { de decisão para melhorias dos processos de correções de rota. }\end{array}$ \\
\hline
\end{tabular}

Fonte: Dados da pesquisa.

Perfil dos decisores da pesquisa

Foram entrevistados 20 gestores do quadro efetivo da Organização Alfa, todos do sexo masculino. $60 \%$ têm idade entre 42 a 46 anos, $10 \%$ entre 47 a 51 anos e $15 \%$ entre 52 a 56 anos. $85 \%$ dos entrevistados possuem mais de 16 anos na empresa. Vários gestores tiveram evolução vertical em suas carreiras, sendo que alguns atuaram, inclusive, em níveis operacionais. Em relação à formação, $50 \%$ ( 10 decisores) possuem ensino superior completo, e $25 \%$ (5 decisores) pós-graduação lato sensu completa. 20\% (4 decisores) não possuem ensino superior ou finalizaram apenas o ensino técnico. Os gestores possuem formação superior diversificada, nas áreas das ciências sociais aplicadas, ciências exatas, ciências da terra e ciências contábeis. Observou-se a existência de relações in- terpessoais verticalizadas, onde um gestor não interage somente com parceiros de um mesmo cargo, mas com várias pessoas com atribuições distintas.

\section{Identificação dos Incidentes Críticos I \\ Decisões Estratégicas mencionadas}

Seção caracterizada pelo registro da tomada de decisão, apoiando-se nas fases do Modelo para Tomada de Decisão Estratégica baseado em Sistemas e Fluxos Informacionais (Quadro 2).

Percepções sobre a influência do uso dos SI na fase de pré-decisão

Dentre as vinte respostas registradas, dezoito entrevistados disseram que algum SI apontou a necessidade de se tomar a decisão indicada por eles: i) sete indicaram o Analítico de Qualidade; ii) dois indicaram o

QUADRO 2 - Síntese dos tipos de decisões registradas pelos entrevistados.

\section{Tomada de decisões registradas - Incidentes Críticos}

Dezoito decisões registradas envolveram situações em que o tema descrito tinha relação com a ação sobre um produto ou serviço interno prestado pelo setor do entrevistado.

Duas decisões descritas tiveram relação com temas gerais, que envolveram outros gestores ou várias áreas (gerentes da organização)

Fonte: Dados da pesquisa. 


\title{
QUADRO 3 - Síntese sobre o uso dos SI na identificação das necessidades de tomada de decisão
}

\begin{tabular}{|c|c|}
\hline Passo 1; Pergunta 1. & Passo 1; Pergunta 2. \\
\hline $\begin{array}{l}\text { Algum sistema de informação da empresa indicou este moti- } \\
\text { vo / necessidade? }\end{array}$ & $\begin{array}{l}\text { Quem foi(ram) responsável(eis) por identificar/despertar para } \\
\text { a necessidade de se tomar essa decisão na sua empresa? }\end{array}$ \\
\hline $\begin{array}{l}\text { Dezoito entrevistados disseram que algum sistema de } \\
\text { informação mostrou o motivo de se tomar a decisão. } \\
\text { Dois entrevistados disseram não ter sido um sistema de } \\
\text { informação que indicou o motivo para a tomada a decisão } \\
\text { registrada por eles. }\end{array}$ & $\begin{array}{l}\text { Os gestores disseram serem eles próprios os responsáveis } \\
\text { por identificarem ou despertarem para a necessidade de se } \\
\text { tomar a decisão na organização. }\end{array}$ \\
\hline
\end{tabular}

Fonte: Dados da Pesquisa.

GP - Gestão da Produção; iii) três indicaram sistemas corporativos, desenvolvidos por terceiros (como o SAP e o ApData); iv) seis disseram que algum SI desenvolvido pelo próprio setor, mas não definiram em especial o nome do sistema. Constatou-se também que a maioria dos gestores disse terem sido eles próprios, juntamente com outros gestores, os responsáveis por identificarem a necessidade de se tomar a decisão na organização.

No passo 2 da fase de pré-decisão, procurou-se identificar quais foram as informações que o entrevistado precisou buscar para tomar a decisão mencionada.

Os entrevistados mostraram-se amparados pelos indicadores contidos nos vários $\mathrm{SI}$, sendo citados como fontes de informação em várias tomadas de decisão. Frases como "eficiência atual do produto", "o histórico de eficiência já alcançado", "o rendimento esperado pela empresa", evidenciaram a utilização do Analítico de Qualidade, amplamente citado. Outras informações demandadas estavam disponíveis em outras fontes de informação:

Necessitei das informações de mercado, do que é aceito e do que é crítico, baseado na gravidade, frequência e no risco.Também precisei das informações do setor de produção de que as ações tomadas já haviam corrigido o problema encontrado nas 600 unidades (DI5).

Para o entrevistado DI 8 informações externas foram o que sustentaram a decisão:

Procurei no mercado um sistema que pudesse substituir o sistema utilizado até o momento. Busquei informações técnicas de sistemas de bombas multiplicadoras (DI8).

No passo 3 da fase de pré-decisão fo-

\section{QUADRO 4 - Síntese sobre os tipos de informações buscadas pelos decisores}

\begin{abstract}
Passo 2; Pergunta 1.
Quais as informações que você precisava para tomar esta decisão? O que buscava?

Respostas com conteúdos sustentados por vários sistemas de informação, isto é, os entrevistados mostraram-se amparados pelos indicadores contidos nestes sistemas, sendo citados como fontes de informação em várias tomadas de decisão.

Frases como "eficiência atual do produto", "o histórico de eficiência já alcançado", "o rendimento esperado pela empresa", evidenciaram quais informações foram necessárias.
\end{abstract}

Fonte: Dados da pesquisa. 


\section{QUADRO 5 - Síntese sobre a identificação das fontes de informação mais utilizadas}

Passo 3; Pergunta 1.

Onde você buscou essas informações? Quais as fontes de informação que você utilizou?

Constatou-se a existência de sistemas de informação que sustentaram ou continham as informações necessárias à

tomada de decisão.

Categorias identificadas nas respostas, quanto às informações necessárias: i) Auditorias de qualidade e de processo; ii) observações diretas sobre o produto ou processo; iii) controle existentes nos setores; iv reuniões informativas; v) assistência técnica; vi) testes práticos.

Fonte: Dados da pesquisa.

\section{QUADRO 6 - Síntese das respostas sobre o processo de busca de informação pelos gestores}

Passo 3; Pergunta 2.

Como você obteve essas informações?

- Dezoito entrevistados citaram as fontes digitais (sistemas de informação integrados utilizados na Organização Alfa) como forma de obtenção das informações;

- Dez entrevistados relataram ter utilizado a comunicação verbal com outros gestores, técnicos e funcionários com atuação operacional como forma de obter as informações que necessitavam para a tomada de decisão;

- Oito entrevistados relataram terem utilizado a observação direta sobre os processos, sobre as formas como as pessoas trabalhavam ou mesmo sobre as máquinas, para obtenção das informações que precisavam para decidir;

- Um entrevistado citou ter feito uso do conhecimento prévio para obtenção da informação;

- Um entrevistado comentou ter utilizado entrevistas para obter as informações que precisava.

Fonte: Dados da pesquisa.

ram consideradas três perguntas.A primeira buscou identificar as fontes de informação utilizadas pelo entrevistado, na busca das informações.

Constatou-se a existência de Sl que continham as informações necessárias à tomada de decisão. A comunicação verbal também serviu como fonte de informação (opiniões e experiências passadas por outras pessoas). Os entrevistados DI, D4 e D20 reforçaram esta percepção:

Busquei informações com os gestores do projeto. Precisei saber deles o número de pessoas envolvidas, os recursos envolvidos na implantação do projeto e os impactos na organização (DI). Não podemos olhar somente para os números. Concluí sobre a neces- sidade de utilizar o conhecimento das pessoas na resolução dos problemas. A informação principal que busquei foi a certeza de que havia um problema de deficiência comportamental. Havia operadores que achavam que não sabiam fazer da forma correta, devido à falta de habilidade (D4). Além do GP para validar o "tamanho do problema", busquei informações com pessoas envolvidas no processo, instrutores e o supervisor do setor, pois tinham relatórios dos registros das interferências (D20).

A $2^{\mathrm{a}}$ pergunta do passo 3 buscou identificar como os entrevistados obtiveram as informações necessárias para a tomada de decisão. 
As respostas foram dadas com alguns destaques para as consultas digitais nos $\mathrm{SI}$ disponibilizados pela organização. Segundo o entrevistado D2:

Eu precisei utilizar avaliações de desempenho dos gestores para conseguir correlacionar as habilidades de cada um com as exigências dos setores dos quais eles atuariam. Diante disso, também busquei na memória as atuações de cada um dos gestores, os problemas já resolvidos e as dificuldades que já tinham passados em cada setor (D2).

O entrevistado D8 relatou ter utilizado observações diretas para obtenção do local em que os produtos apresentavam as quebras:

Precisei acompanhar o deslocamento dos produtos para conseguir identificar a região do produto que quebrava. Isto me ajudou a avaliar também o trajeto, que apresentava vários problemas no piso e que podiam estar relacionados com as quebras das peças (D8).

A $3^{\mathrm{a}}$ pergunta buscou entende os moti- vos pelos quais os entrevistados escolheram as fontes citadas anteriormente, procurando identificar aspectos relacionados à acessibilidade, o tempo e o custo de acesso, a qualidade, a importância, a confiabilidade, relevância e pertinência das fontes de informação reconhecidas pelos entrevistados.

Ficaram caracterizados, nos relatos dos entrevistados, dois principais aspectos quanto ao motivo da escolha das fontes de informação: a disponibilidade e a segurança. E a facilidade de acesso e a segurança estavam relacionadas aos sistemas de informação disponíveis.

O $4^{\circ}$ passo, último da fase da pré-decisão, constou de apenas uma pergunta, que buscou identificar se as informações obtidas pelo entrevistado foram efetivamente encontradas e se estas serviram para ajudá -lo na tomada de decisão.

Todos os entrevistados disseram ter encontrado as informações que precisavam, e apresentaram respostas que variaram de acordo com o Incidente Crítico de cada um. Vários SI comuns foram citados como fornecedores das informações que serviram efetivamente à tomada de decisão.

QUADRO 7 - Síntese dos principais critérios para escolha de fontes de informação

Passo 3; Pergunta 3.

Por que você escolheu essas fontes de informação?

Caracterizados nos relatos dos entrevistados dois principais aspectos quanto ao motivo da escolha das fontes de informação: a disponibilidade e a segurança nas fontes de informação.

Fonte: Dados da pesquisa.

QUADRO 8 - Síntese do conteúdo informacional obtido para a tomada de decisão

\begin{abstract}
Passo 4; Pergunta 1.
Quais informações você conseguiu para tomar sua decisão? As informações que você buscava foram encontradas? Serviram para ajudá-lo no momento de sua decisão?

Todos os entrevistados disseram ter encontrado as informações que precisavam.

Vários sistemas de informação comuns foram citados como fornecedores das informações que serviram efetivamente à tomada de decisão.
\end{abstract}

Fonte: Dados da pesquisa. 
Eu fiz um desdobramento dos defeitos de forma que relacionei os mesmos com o problema relatado. Tive que buscar a eficiência das peças no Analítico e fazer uns gráficos para elencar as prioridades (D3).

Todas as informações foram obtidas nos sistemas de informação: a incidência de quebras referente ao problema e a estratificação. Para informações mais específicas, tive que criar testes para validar a condição proposta (D8).

Outros entrevistados também relataram que, além dos SI, as informações foram encontradas via observação direta do processo ou pelo feedback dado por outros gestores sobre o problema gerado.

Percepções acerca da influência do uso dos SI na fase de decisão

Observou-se que treze entrevistados relacionaram nas respostas influências originadas diretamente dos $\mathrm{SI}$, o que ficou reforçado nos relatos dos entrevistados D5, DI4 e DI9:

O mais relevante veio do GP, que mostrou após as análises que haviam oportunidades no ganho da produtividade. Eu sei que tive que fazer várias observações, mas a possibilidade de melhorar o "meu número" falou mais alto (D5).

Os sistemas de informação da qualidade foram mais relevantes. Verificar que o índice de deformação do produto não estava em conformidade com padrões considerados pela empresa me chamou muito a atenção (DI4).

A informação mais relevante e que influenciou a decisão foi a quantidade de problemas associados à manutenção do sistema, bem como a quantidade de peças substituídas durante um período (DI9).

Houve relatos em que a observação direta reforçou as informações obtidas pelos SI. Após toda a análise, constatei que não havia "uma equipe" no setor, não havia a interação das pessoas com esta finalidade. As informações que vieram das pessoas, dos funcionários do setor, foi o que mais influenciou a decisão a ser tomada (D4).

Alguns apontaram para a tomada de decisões influenciada pela experiência prévia e até mesmo para a criação de um novo SI individual, para utilização do próprio gestor. Olha, eu precisava tornar a rotina estável, o que não estava acontecendo. Então, alguns pontos foram necessários e me influenciaram: Precisava de uma rotina, conhecia as características dos diferentes postos de gestão e passei a estudar as características dos gestores e em quais postos elas meIhor seriam aproveitadas. A descoberta da possibilidade em unir estes dois aspectos foi decisivo e me influenciou

QUADRO 9 - Síntese sobre o que mais influenciou nas decisões citadas pelos gestores

Passo 5; Pergunta 1.

Com base nas informações que obteve, o que mais influenciou na sua decisão final?

Treze entrevistados relacionaram nas respostas influências originadas diretamente dos sistemas de informação.

Experiência prévia e até mesmo a criação de um novo sistema de informação individual.

Fonte: Dados da pesquisa. 
consideravelmente para tomar a decisão (D2).

Foi uma decisão tomada a médio prazo. Dentro deste prazo de avaliação, houve a confirmação de que do funcionário não se poderia extrair mais nada além da sua entrega até o momento. O Feedback de outros gestores foi o que mais influenciou a minha tomada de decisão (DI3).

Percepções acerca da influência do uso dos SI na fase de pós-decisão

O entrevistado D2 considerou a implementação da tomada de decisão a partir de avaliações dos indicadores de desempenho e a observação do gestor quanto ao comportamento de cada um deles. Algumas implementações culminaram em desenvolvimento de novos sistemas de controle e de informação, conforme relatado pelos entrevistados DI0 e DI9:

Desenvolvemos um sistema para acompanhamento interno da produção, com definições de contagens diárias dos estoques. Definimos ainda um indicador que envolvia a quantidade de moldes produzidos diariamente, por fundidor, adotando uma avaliação quantitativa dos check list realizados pelos supervisores de fundição, meus clientes (DI0).

Após estudos que realizamos, sobre a viabilidade do sistema, foi instalado um sistema automatizado de controle e informação do consumo de água dos poços artesianos, que contou com indicadores horários de consumo, com alertas do limite outorgado e desligamento automático caso o limite seja alcançado (DI9).

Houve também implementações que envolveram a criação de dispositivos e novas peças para equipamentos, como relata o entrevistado D20:

Fizemos testes de um protótipo que reforçasse as partes que apresentavam necessidade de substituição. Após a aprovação, o protótipo foi implementado em todos os outros equipamentos que apresentavam o mesmo problema (D20).

No sétimo passo do modelo, buscou-se o entendimento sobre a avaliação da decisão tomada.

Todos os gestores se utilizaram de algum procedimento para avaliar a tomada de decisão relatada. Dezessete destes re-

QUADRO 10 - Síntese das respostas: Formas de implementação da decisão

Passo 6; Pergunta 1.

Depois de tomada a decisão, como ela foi implementada / colocada em prática?

- Implementação com o uso de ferramentas da qualidade como o PDCA.

- O uso de reuniões informativas, aplicações de instruções de trabalho também foram recursos considerados e que apoiaram na implementação.

- Desenvolvimento de novos sistemas de controle e de informação.

- Criação de dispositivos e novas peças para equipamentos.

- Mudança e adaptações em equipamentos.

- Auditorias de processo e de produtos.

Fonte: Dados da pesquisa. 
QUADRO 11 - Procedimento para avaliação da decisão e o uso de sistemas para este fim

\begin{tabular}{|l|l|}
\hline $\begin{array}{l}\text { Passo 7; Pergunta 1. } \\
\text { Houve algum procedimento para avaliar a decisão } \\
\text { tomada e implementada? }\end{array}$ & $\begin{array}{l}\text { Passo 7; Pergunta 2. } \\
\text { Como os sistemas de informação auxiliaram na avaliação da tomada de } \\
\text { decisão? }\end{array}$ \\
$\begin{array}{l}\text { Todos os entrevistados relataram ter utilizado } \\
\text { um procedimento para avaliar a tomada de deci- } \\
\text { são relatada por eles. }\end{array}$ & $\begin{array}{l}\text { Dezessete entrevistados relataram ter utilizado um sistema de infor- } \\
\text { mação como apoio na avaliação da tomada de decisão. } \\
\text { "Indicadores do nosso processo". } \\
\text { "O cronograma de execução das tarefas do setor mostrou evolução". }\end{array}$ \\
\hline
\end{tabular}

Fonte: Dados da pesquisa.

lataram ter utilizado um SI como apoio na avaliação da tomada de decisão.

Sim. Foram considerados os indicadores do nosso processo. Utilizei os resultados de desempenho dos nossos produtos. Então, criei um diagrama com as características de cada gestor. Também considerei as necessidades de cada posto de gestão. Como fonte de informação dos resultados de processo, utilizei o Analítico de qualidade para obter a performance dos produtos em cada processo (D2).

O Analítico de qualidade auxiliou na forma de direcionar os esforços. Este sistema mostrou o desdobramento dos resultados obtidos antes e depois da tomada de decisão. Então pude entender que estávamos no caminho certo (D4).

A decisão em si envolvia a redução da velocidade de deslocamento das máquinas. Tive que acompanhar e observar o processo de deslocamento e estabilidade das peças com o novo limite de velocidade. O GP auxiliou como um sistema que tem o registro dos tempos de operação e dos métodos (D8).

O entrevistado DI3 relata ter utilizado outras formas de avaliação juntamente com os Sl:
O cronograma de execução das tarefas do setor mostrou evolução após a tomada de decisão. Os indicadores de qualidade mostraram a evolução dos produtos. Além disso, os feedbacks de outros gestores auxiliaram efetivamente. $O$ problema de relacionamento com os outros funcionários também foi resolvido (DI3).

O passo 8 direcionou duas perguntas aos entrevistados, com a finalidade de identificar, na I $\mathrm{I}^{\mathrm{a}}$ questão, se a tomada de decisão foi registrada, quem foi o autor do registro e quais os motivos deste registro. A $2^{\mathrm{a}}$ pergunta teve o objetivo de identificar se algum sistema de informação foi utilizado para se fazer o registro e, se estes sistemas apresentaram os recursos adequados para tal fim.

Dezoito dos vinte entrevistados relataram que a decisão tomada foi registrada, e também afirmaram ter utilizado SI para este fim. No entanto, outros meios de registro também foram utilizados. Para o entrevistado D5, o registro ficou formalizado na utilização de um procedimento operacional padrão, convertendo as decisões em ações descritas, passo a passo. $O$ entrevistado D8 afirma ter utilizado registros procedimentais de tempos de operação, no GP e no Krontime. Para o entrevistado D I9, Utilizamos o SAP, através das ordens 


\title{
QUADRO 12 - Registro das decisões e o uso de SI para este fim
}

\begin{tabular}{|l|l|}
\hline Passo 8; Pergunta 1. & Passo 8; Pergunta 2. \\
$\begin{array}{l}\text { Esta decisão foi registrada, de alguma forma, } \\
\text { na empresa? }\end{array}$ & $\begin{array}{l}\text { Quais sistemas de informação são utilizados para este registro? Eles apre- } \\
\text { sentam os recursos adequados para o registro? }\end{array}$ \\
\hline $\begin{array}{l}\text { Dezoito dos vinte entrevistados relataram } \\
\text { que a decisão tomada foi registrada. }\end{array}$ & $\begin{array}{l}\text { Os mesmos entrevistados que responderam positivamente também } \\
\text { afirmaram terem utilizado sistemas de informação para este fim. }\end{array}$ \\
& $\begin{array}{l}\text { SAP; GP /Krontime; Nove entrevistados relataram entre outras formas de } \\
\text { registro, a utilização de e-mails para registro. }\end{array}$ \\
\hline
\end{tabular}

Fonte: Dados da pesquisa.

\section{QUADRO 13 - Divulgação da decisão para outros gestores e o uso de SI para este fim}

\begin{abstract}
Passo 9; Pergunta 1.
Esta decisão foi divulgada para outros gestores? Quais sistemas de informação foram utilizados para a divulgação?

Relatos de diversas formas de divulgação.

Apenas dois entrevistados não consideraram que a decisão tomada foi divulgada.

Quatorze indicaram que o meio de divulgação ocorreu em reuniões.

Quatorze entrevistados relataram a utilização dos sistemas de informação utilizados como meio de divulgação da tomada de decisão.
\end{abstract}

Fonte: Dados da pesquisa.

de comprar das peças, desenho técnico da nova instalação, prevendo a eliminação dos dispositivos antigos e instalação dos novos boosters (D/9).

O Entrevistado DI0, reforça a importância dada ao registro:

A ideia era, então, registrar todas as informações e fazer a relação entre o cumprimento da produção e as verificações geradas pelos supervisores. Para isso, utilizei planilhas eletrônicas e formulários (DI0).

Nove entrevistados destacaram a utilização de e-mails para registro da tomada de decisão.

O nono passo, último do modelo, buscou identificar se houve divulgação da tomada de decisão relatada. Assim, a seção contou com uma pergunta que buscou também o entendimento sobre quais SI foram utilizados ou que serviram à divulgação da tomada de decisão.
Apenas dois afirmaram que a decisão tomada não foi divulgada (D2 e D6), afirmando que apenas o compartilhamento da tomada de decisão com o superior imediato foi feita. $O$ entrevistado $D I$ relatou que a divulgação da tomada de decisão foi realizada através de apresentações aos outros gestores, além da confecção de um book fotográfico e cronológico. Quatorze entrevistados indicaram que o meio de divulgação se deu a partir de reuniões, com a presença dos gestores da Organização Alfa. Outro meio de divulgação citado por oito dos entrevistados referiu-se ao e-mail.

Quatorze entrevistados relataram o uso de SI para divulgação da tomada de decisão. $O$ entrevistado DI 6 relatou que a divulgação foi realizada via utilização de um SI corporativo, no qual as regras e normas foram inseridas para que outros gestores pudessem ter acesso. Este SI conta com a possibilidade de confecção de relatórios, 
que explicam os ganhos obtidos com a decisão tomada.

\section{CONSIDERAÇÕES FINAIS}

Este trabalho teve como objetivo principal analisar como os SI são usados nos processos de tomada de decisão em uma organização de grande porte com fins à produção de louças sanitárias, denominada neste trabalho como Organização Alfa. $\mathrm{O}$ primeiro objetivo específico buscou descrever as funcionalidades dos SI utilizados na organização. Ficou evidente que os SI disponíveis na Organização Alfa contam com recursos e indicadores que mantêm estreita relação com a rotina dos gestores. Estes sistemas apresentam finalidades variadas, possibilitando ao gestor explorar diversas informações para decidir uma ação sobre uma situação ou problema, desde melhorias em produtos, em processos de inovação, na produção, na condução do fluxo produtivo, na avaliação das tarefas ou mesmo nos controles relacionados aos recursos humanos.

Associada a estas características surgiu outra observação durante a análise, que diz respeito à capacidade que estes sistemas têm em manter informações que atendam a todos os níveis da organização. Outro aspecto importante observado na realidade da Organização Alfa foi que, ao mesmo tempo em que foram identificados SI corporativos, e mesmo sistemas terceirizados com recursos definidos pelos seus fornecedores, também se observou a existência de SI desenvolvidos pela organização e até mesmo pelos gestores, que apresentaram recursos específicos, ora para sustentar as decisões tomadas, ora para armazenamento de dados locais. Ainda sobre as funcionalidades dos SI utilizados, ressalta-se a capacidade de interação que os mesmos possuem, ora complementando-se para entregar ao usuário uma informação mais estratificada dos processos, ora disponibilizando a informação mais geral, facilitando a análise de cenários.

Ficou evidenciado, nos primeiros passos do Modelo para Tomada de Decisões Estratégicas baseado em Sistemas e Fluxos Informacionais, que as características e funcionalidades dos SI são importantes e levadas em consideração pelos gestores durante o processo decisório. Reforçando esta visão, a maioria dos entrevistados afirmou utilizar e obter informações a partir dos SI disponíveis.

Durante as entrevistas vários gestores relataram ter feito a divulgação da tomada de decisão, bem como dos resultados obtidos. Tal divulgação foi efetivada principalmente por reuniões gerenciais que ocorrem mensalmente. Neste sentido, o modelo proposto no trabalho manteve importante consonância com as funcionalidades dos SI levados em conta nos processos decisórios estudados. Em todas as fases do processo de decisão considerado no modelo, as funções dos sistemas mostraram eficácia na condução analítica da decisão.

O segundo objetivo específico buscou identificar quais os fatores e sistemas são utilizados pelos gestores nos processos de decisão. Percebeu-se que os SI estão presentes nos processos de decisão, sobretudo suportando com informações sobre os processos de produção, dos resultados e de pessoas. Ficou destacado o uso disseminado do SI Analítico de Qualidade. No dia-a-dia, as informações obtidas a partir deste sistema são discutidas em reuniões setoriais, reuniões para desenvolvimento de produtos e processos, além de servirem 
como referência para processos internos e externos, quando comparados com outras unidades, em outras regiões do país.

Outros sistemas também apresentam usos frequentes e similares ao Analítico de Qualidade. O GP (Gestão da Produção) destacou-se como fonte de informação, por conter informações relevantes para a tomada de decisão e por acumular dados e informações oriundas de todos os setores da organização, oferecendo aos gestores diversas formas de análises e comparações de produtividade, dos procedimentos operacionais, da evolução dos processos e dos rendimentos dos postos de trabalho. Numa visão participativa, foi possível verificar ser este sistema capaz de oferecer informações precisas e atualizadas da evolução produtiva da organização, além de manter um padrão de informação que possa ser comparado com outras fábricas, em outras regiões.

Um fator importante destacado pelos entrevistados diz respeito ao uso da observação direta sobre os processos, como forma de obter informações e tomar as decisões. Alguns gestores comentaram ser a observação a principal fonte de informação na tomada de decisão. Foi possível constatar ser a observação direta uma característica marcante na rotina dos gestores, devido à natureza dos processos produtivos e sua relação com outros gestores e trabalhadores operacionais.

O Modelo para Tomada de Decisões Estratégicas baseado em Sistemas e Fluxos Informacionais adequou-se eficazmente aos SI utilizados, bem como aos fatores a eles associados, às categorias de uso das informações e suas especialidades, corroborando os efeitos das decisões tomadas pelos entrevistados quando os sistemas foram utilizados.
O terceiro objetivo específico buscou identificar como os SI suportam as decisões tomadas pelos gestores. Ficou evidenciado que, na fase de pré-decisão, os SI utilizados sustentam as informações relevantes à tomada de decisão, assegurando as análises e apoiando os gestores. A fase que caracterizou o momento da decisão propriamente dito ficou marcada nas entrevistas pela influência das informações contidas nos sistemas e que serviram para a tomada de decisão dos gestores.

$\mathrm{Na}$ fase de pós-decisão os sistemas são importantes e utilizados nos passos relacionados à avaliação, ao registro e à divulgação da decisão. Houve maior apoio e suporte dos sistemas nas fases que mencionam a avaliação e o registro da decisão. Foi constatado que o fato dos sistemas acumularem informações e dados ao longo de um tempo relativamente prolongado, permite aos gestores avaliações de cenários e situações ao longo de períodos que favorecem a avaliação da tomada de decisão. Esta característica foi observada em todos os sistemas utilizados pela organização.

O presente trabalho demonstrou, portanto, que os SI são, efetivamente, utilizados nos processos de tomada de decisão na Organização Alfa, considerando todas as fases do Modelo para Tomada de Decisões Estratégicas baseado em Sistemas e Fluxos Informacionais.

Recomenda-se novos estudos que possam pôr à prova o modelo de tomada de decisão utilizado neste trabalho, em situações onde as rotinas organizacionais são preenchidas por ambientes de incerteza, cujos produtos ou serviços originam-se de processos de inovação ou mesmo onde a criatividade seja um constructo de destaque para a tomada de decisão. 
ALLISON, G. T. Essence of Decision: Explaining the Cuban Missile Crisis. Boston: Little Brown, I97I.

ALVARENGA NETO, R.D.C. Gestão do Conhecimento em Organizações: Proposta de Mapeamento Conceitual Integrativo. Curitiba: Saraiva, 2008.

ANGELONI, M.T. Elementos intervenientes na tomada de decisão Tomada de decisão. Ciência da Informação, Brasília, v.32, n.I, p.| 7-22, 2003.

AUDY, N.J.L.; ANDRADE, G.K.; ClDRAL, A. Fundamentos de Sistemas de Informação. [VitalSource Bookshelf Online], 20I I. Disponível em: https://integrada.minhabiblioteca.com.br/\#/ books/978857780I305/. Acesso: 25 de Abril de 2016.

BARBOSA, R.R. Gestão da informação e do conhecimento: origens, polêmicas e perspectivas. Informação \& Informação, Londrina, v. I3, n.esp., p. I-25, 2008.

BARDIN, L. Análise de Conteúdo. Lisboa: edições 70, 2002.

BIO, S.R. Sistemas de Informação: um enfoque gerencial. São Paulo:Atlas, 1996.

BRUYNE, P. Dinâmica da Pesquisa em Ciências Sociais: os pólos da prática metodológica. Rio de Janeiro: Francisco Alves, I99I.

CARROLL, J.M.; ALTY, J.; DIAPER, D.; GUEST, F.C. Critical incidents and critical threads in empirical usability evaluation. People and Computers VIII, Proceedings of the HCl'93 Conference. Cambridge: Cambridge University Press, p. 279-292, 1993.

CHOO, C.W. The knowing organization: how organizations use information to construct meaning, create knowledge, and make decisions. $2^{\mathrm{a}}$ Ed. New York: Oxford University Press, 2006.

COHEN, M. D., MARCH, J. G., OLSEN. A Garbage Can Model of Organizational Choice. Administrative Science Quarterly, v.I7. n. I, p.I-25, 1972.

COLLIS, J; HUSSEY, R. Pesquisa em administração: um guia prático para alunos de graduação e pós graduação. $2^{\mathrm{a}}$ ed. Porto Alegre: Bookman, 2005.

COOPER, D.R.; SCHINDLER, P.S. Métodos de Pesquisa em Administração. $10^{a}$ ed. Porto Alegre: Bookman, 20I I.

CUNHA, I.B.A.; MAFRA PEREIRA, F.C.; NEVES, J.T.R.Análise do Fluxo Informacional presente em uma empresa do segmento de Serviços de Valor Agregado (SVA). Perspectivas em Ciência da Informação, Belo Horizonte, v.20. n.4, p.I07-I28, out./dez., 2015.

DAVENPORT, T.H. Ecologia da Informação. New York: Oxford University, 1999.

EIN-DOR, P.; SEGEV, E. Administração de Sistemas de Informação. Rio de Janeiro: Campus, 1983. ESTENDER, A.C.; BARBOSA, L.D.O.S.; SANTOS, D.P.D. Gestão da informação: a comunicação interna nas empresas. Revista de Administração da Fatea, v. I I, n. II, 2016.

FIGUEIREDO, N.M.A. Método e metodologia na pesquisa científica. $2^{\mathrm{a}}$ ed. São Caetano do Sul, São Paulo, Yendis Editora, 2007.

FLANAGAN, J. C.The critical incident technique. Psychological Bulletin, American Institute for Research and University of Pittsburgh, v.5 I, n.4, p.327-358, July 1954.

FURLAN, J.D.; IVI, I.M.;AMARAL, F.P.Sistema de Informação Executi-
va=EIS-Executive Information System: como integrar os executivos ao sistema informacional das empresas, fornecendo informações úteis e objetivas para suas necessidades estratégicas e operacionais. São Paulo: Makron Books, 1994.

GIL,A.C. Como elaborar projetos de pesquisa. 4a ed. São Paulo: Atlas, 2002.

GORDON, R.S.; GORDON, R.J. Sistemas de Informação - Uma Abordagem Gerencial. 3a edição, 2006. [VitalSource Bookshelf Online]. Disponível em: https:// integrada.minhabiblioteca.com. br/\#/books/978-85-2 I6-239l-5/. Acesso em: 23 de abril de 2016 .

GUIMARÃES, J.A.C.O profissional da informação sob o prisma de sua formação. In: VALENTIM, M.L.P. (Ed.). Profissionais da Informação: formação, perfil e atuação profissional. São Paulo: Polis. p.53-70, 2000.

LAUDON, K.C.; LAUDON, J.P. Sistemas de Informação Gerencial: Administrando a empresa digital. 9a ed. São Paulo: Pearson Prentice Hall, 20I I.

LIMA, E.A.D. Arquitetura de sistemas de informação: proposta de um mecanismo de aprendizagem com orientação metodológica para apoio à decisão em cenários complexos. 2015. Disponível em: http://repositorio.unb.br/bitstream/I0482/I8059/I/20 I5_EliomarAraujoLima.pdf. Acesso: 10 de Abril de 2016.

MAFRA PEREIRA, F.C. Fundamentos Metodológicos da Pesquisa de Marketing. 68p. Monografia (Especialização lato sensu em Gestão Estratégica de Marketing) - Centro de Pós-Graduação e 
Pesquisas em Administração da Universidade Federal de Minas Gerais, Belo Horizonte, 2000.

MAFRA PEREIRA, F.C. Comportamento Informacional na Tomada de Decisão: Proposta de Modelo Integrativo. Tese de Doutorado em Ciência da Informação - ECl / UFMG. Belo Horizonte - Minas Gerais: Escola de Ciência da Informação da Universidade Federal de Minas Gerais (ECI/UFMG), 20I I.

MAFRA PEREIRA, F.C. Modelo Integrativo sobre Comportamento Informacional em Processos Decisórios. Revista de Administração FACES Journal, Belo Horizonte, v.15, n.3, p.27-49, jul./ set., 2016.

MAlHOtRA, N. K. Pesquisa de Marketing: uma orientação aplicada. $3^{\mathrm{a}}$ edição. Porto Alegre: Bookman, 200l.

MARCH,J. G. A Primer on Decision Making: how Decisions $\mathrm{Ha}$ ppen. Nova York: Free Press, 1994.

MARCH, J. G., SIMON, H. A. Limites cognitivos da racionalidade. In: Teoria das organizações. Rio de Janeiro: Fundação Getúlio Vargas, cap. 6, p. 192-220, 1975.

MATTAR, F.N. Pesquisa de Marketing. São Paulo:Atlas, 1996.

MAZZOTTI, A.A.; GEWANDSZNAJDER, F. O método nas ciências naturais e sociais: pesquisa quantitativa e qualitativa. São Paulo: Pioneira, 1999.

MELTSNER, A.J. Policy Analysts in the Bureaucracy. Berkeley: University of California Press, 1976.

MINTZBERG, H. Ascensão e queda do Planejamento estratégico. 2014. [VitalSource Bookshelf Online]. Disponível em: https://integrada.minhabiblioteca.com.br/\#/ books/978857780 I237/. Acesso em: 21 de outubro de 2015.

MINTZBERG, H., RAISINGHANI, D., THÉORÊT, A., The Structure of 'Unstructured' Decision Processes. Administrative Science Quarterly, v.2I, no. 2, p. 246-275, 1976.

MORAES, G.D.A;ESCRIVÃO FILHO, E.

A gestão da informação diante das especificidades das pequenas empresas. Ciência da Informação, Brasília, v.35, n.3, p.I24- I 32, 2006.

NASH,J.F;; ROBERTS, M.B. Accounting Information Systems. MacMillan Publishing Co.: New York, 1984.

OLIVEIRA, A.A.D. Observação e entrevista em pesquisa qualitativa. Revista FACEVV, v.4, p.22-27, 2010.

OLIVEIRA, D.P.R. Sistemas de Informações Gerenciais. I6a edição. São Paulo:Atlas, 2014.

PEREIRA, B.M.D.; FONSECA, M.J.G. Série Gestão Estratégica - Faces da Decisão - Abordagem Sistêmica do Processo Decisório. 2009. [VitalSource Bookshelf Online]. Disponível em:https://integrada.minhabiblioteca.com.br/\#/ books/978-85-2I6-2276-5/. Acesso em: 28 de outubro de 2015.

PFEFFER, J.; SALANCIK, G. R. Organizational Decision Making as a Political Process: the Case of a University Budget. Administrative Science Quarterly, 19 (2), p.|35-I5I, 1974.

REZENDE, D.A.; ABREU, A.F. Tecnologia da informação aplicada a sistemas de informação empresariais: o papel estratégico da informação e dos sistemas de informação nas empresas. 3a ed. São Paulo: Atlas, 2003.

SANDAY, P.R. The ethnographic paradigma. In:Van Haanen, J. (ed.) Qua- litative methodology. Bervely Hills, Sage Publ., 1984.

SCHWARTZ, G. Science in Marketing. New York: John WHey, 1970. SILVA, R.O.; RODRIGUES, L.M.; SILVA, M.S. A Importância dos Sistemas de Informação na Gestão de Empresas. Tecnologias Em Projeção, v.6, n.2, p.37-47, 2015. Disponível em: http://revista.faculdadeprojecao.edu.br/index.php/ Projecao4/article/view/543/497. Acesso: 18 de Abril de 2016.

SIQUEIRA, J. O sistema de custos como instrumento de apoio ao processo decisório: Um estudo multicaso em indústrias do setor metal-mecânico da Região Noroeste do Estado do Rio Grande do Sul. Dissertação de Mestrado apresentada à Universidade Regional do Noroeste do Estado do Rio Grande do Sul - UNIJUÍ, como requisito para obtenção do título de Mestre em Desenvolvimento, Gestão e Cidadania, 2005.

SPRAGUE, R.H.E.;WATSON, H.J. Sistemas de apoio à decisão: colocando a teoria em prática. Rio de Janeiro: Campus, 1991.

STAIR, R.M. Princípios de sistemas de informação: uma abordagem gerencial. Rio de Janeiro: Livros Técnicos e Científicos, 1998.

TARAPANOFF, K. (Org.). Inteligência Organizacional e Competitiva. Brasília: Ed. Universidade de Brasília, 2006.

TRIVIÑOS, A.N.S. Introdução à pesquisa em ciências sociais. São Paulo. Atlas, 1987.

VERGARA, S.C. Projetos e Relatório de Pesquisa em Administração. 3a ed. São Paulo:Atlas, 2007.

YIN, R.K. Estudo de caso: planejamento e métodos. Trad. Daniel Grassi. Porto Alegre, Bookman, 2005. 